\title{
Enhancing nitrogen availability, ammonium adsorption-desorption, and soil pH buffering capacity using composted paddy husk
}

\begin{abstract}
Form of nitrogen present in soils is one of the factors that affect nitrogen loss. Nitrate is mobile in soils because it does not absorb on soil colloids, thus, causing it to be leached by rainfall to deeper soil layers or into the ground water. On the other hand, temporary retention and timely release of ammonium in soils regulate nitrogen availability for crops. In this study, composted paddy husk was used in studies of soil leaching, buffering capacity, and ammonium adsorption and desorption to determine the: (i) availability of exchangeable ammonium, available nitrate, and total nitrogen in an acid soil after leaching the soil for 30 days, (ii) soil buffering capacity, and (iii) ability of the composted paddy husk to adsorb and desorb ammonium from urea. Leaching of ammonium and nitrate were lower in all treatments with urea and composted paddy husk compared with urea alone. Higher retention of soil exchangeable ammonium, available nitrate, and total nitrogen of the soils with composted paddy husk were due to the high buffering capacity and cation exchange capacity of the amendment to adsorb ammonium thus, improving nitrogen availability through temporary retention on the exchange sites of the humic acids of the composted paddy husk. Nitrogen availability can be enhanced if urea is amended with composted paddy husk.
\end{abstract}

Keyword: Adsorption; Ammonium; Composted paddy husk; Desorption; Nitrogen; Nitrate 